\section{ELECTRIC DISCHARGE IN GASES}

I.

$\mathrm{IN}$ a paper read some time since at the Royal Society, ${ }_{i}{ }^{1}$ Drs. Warren De La Rue and Hugo W. Muiller gave the first part of an account of their researches on the electric discharge in gases. This part, of which we shall at present give some account, consists mainly of a discription of the apparatus employed in this research, and of the results of their experiments with gases at atmospheric pressure and pressures down to I4I millimetres. They have since communicated to the Royal Society a second part, which treats of the discharge in highly rarefied gases (vacuum tubes).

The source of electrification used by Messrs. De La Rue and Müller was a battery of chloride of silver elements; commencing with 1,000 , the authors have from time to time increased the number of cells to $I I, 000$ joined in series (I, 330 volts). In spite of its containing a somewhat costly material, this element, when compared with the many other forms of voltaic cell at present in use, possesses points of advantage such as render its general adoption extremely probable; we therefore transcribe in considerable detail the authors' description of it in its present improved form.

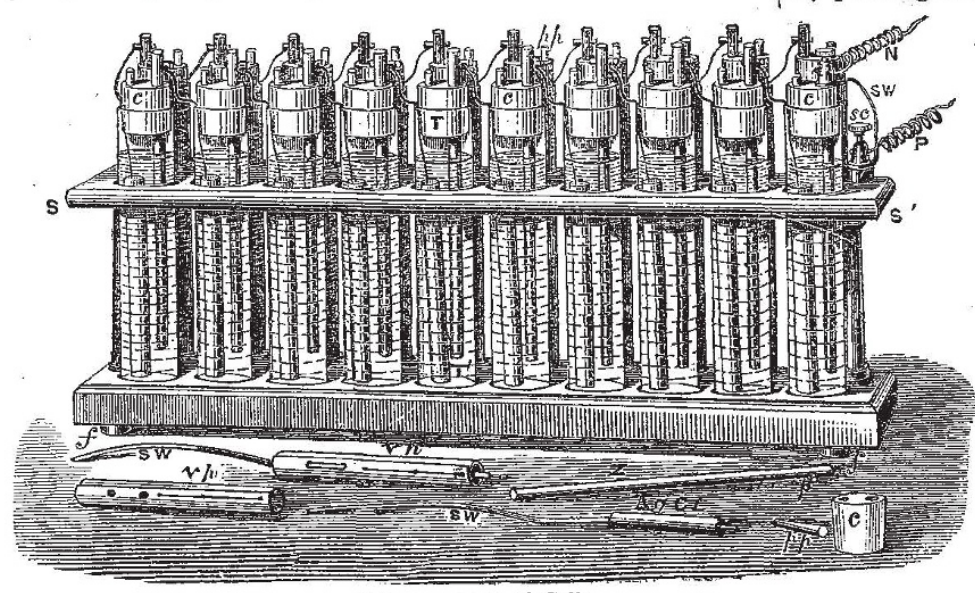

FIG. 1. -Nest of Cells.

Fig. I shows a nest of twenty cells of the most recent construction; the several components of the cells are given separately at the base of the stand. The glass tube $\mathrm{T}$ is $5 \frac{1}{2}$ inches high, and $\mathrm{r} \frac{1}{8}$ inch in diameter: it has a flat bottom. The stopper $c$ is of paraffin, and is perforated with two holes, one for the zinc rod $(z)$ to pass through, the other for letting in the liquid; the latter is ultimately closed with a paraffin plug $(p p)$. Cork and india-rubber stoppers were tried and abandoned. The zinc is obtained of the Belgian Vieille Montagne Company. When it is intended to keep a battery more than a year in action the zincs should not be amalgamated, as the silver wires in contact with them would gradually be rotted through. Platinum, which would not become amalgamated, might have been substituted for the silver wires; but it would have cost $55 l$. extra per $\mathrm{I}, 000$ cells. The zinc rods are $15 \mathrm{~cm}$. long, $0.56 \mathrm{~cm}$. in diameter, and perforated at the top with a hole $0.25 \mathrm{~cm}$. in diameter. The chloride of silver $(\mathrm{AgCl})$ is cast in the form of a rod on a flattened silver wire $\mathrm{S} \mathrm{W}$; the rods are $5.4 \mathrm{~cm}$. long, $0.762 \mathrm{~cm}$. in diameter, and weigh I2:97 grms. The silver wires are $20 \mathrm{~cm}$. long, $0.127 \mathrm{~cm}$. wide, and $0.0229 \mathrm{~cm}$. thick, weighing $0.88 \mathrm{gms}$. each; they protrude slightly beyond the bottom of the rod of chloride, as will be seen from the figure. The wires and Phil. Trans., clxix. pp. 55-r22. rods were obtained from Messrs. Johnson and Matthey, of Hatton Garden; the cost, including labour of casting, amounted to $2 s$. per cell. $v p$ is a cylinder of three folds of vegetable parchment; at its lower end the folds are stitched together with thread, and at the upper part they are interlaced.with the silver wire, and thus prevented from unfurling. The object of the parchment cylinder is to prevent the reduction of the chloride of silver rod, which would result from its accidental contact with the zinc. By giving proper bends to the silver wire before making up the cell it is easy to cause the chloride rod to lie vertically and press gently against the glass wall.

The liquid used for the cells is a solution of chloride of ammonium, 23 gms. to I litre of distilled water; by making use of a glass siphon with a long arm of indiarubber tubing, provided with a pinch cock, and terminating in a glass tube drawn down to enter freely into the hole in the paraffin stopper, it was found that 2,400 cells could be charged by one person in ten hours.

In making up a battery the glass cells are first arranged in their nests; next the paraffin stoppers are fitted with zincs; then the chloride rods are inserted and the cell closed with the stopper, the thin silver wire passing between the glass and the paraffin. When these operations have been performed for all, the cells are joined up by passing the silver wire of each cell through the hole in the zinc rod of its neighbour, and securing it there by pressing in a taper brass plug $p$ with a pair of pliers. Ultimately, the cells having been charged with fluid, as already described, and closed by the insertion of $p p$, a hot iron is run round the outside of the stopper and round the zinc rod to secure the latter in its place, and make tight the joints by the melting and re-setting of a little paraffin.

Thus set up, the battery has an electromotive force of about $\mathrm{I} \circ 3$ volt and internal resistance of not more than 5 ohms per cell : the former remains remarkably constant, but the latter increases, especially in cells that are left long idle. This rise in internal resistance is caused by a skin of oxychloride of zinc, which gradually forms on the zincs in all batteries where the zincs are immersed in a neutral chlorine compound. The battery may be restored to its original resistance by removing and scraping the zinc rods, but a more expeditious mode is to withdraw the small paraffin plug used to close the hole in the stopper through which the cells are charged, and to introduce into each cell, containing 50 c.c., I c.c. of pure hydrochloric acid, sp. gr. I 16 , containing $3 I^{\circ} 8$ per cent. $\mathrm{HCl}$ gas, equivalent to $0.3689 \mathrm{gm}$. acid. Before introducing it into the cells, as is conveniently done by means of a graduated pipette furnished with a stop-cock, it is better to dilute the acid with an equal volume of distilled water. An effervescence takes place, and it is therefore necessary to allow the tubes to remain open twenty-four hours before the small paraffin plug is replaced, in order to permit the hydrogen, which is generated, to escape. It required two days for one person to perform this operation on a battery of 1,200 cells. The acid dissolves $0.3295 \mathrm{gm}$. of zinc or its equivalent of oxide.

After having been in almost daily use on circuits comparable with those occurring in overland telegraphy, it was found that in two batteries the amount of $\mathrm{AgCl}$ reduced in sixteen months averaged 4.57 gms. per cell, while in two other batteries which had been worked for ten months the reduction amounted to $3.57 \mathrm{gms}$. per cell.

An accident enabled the authors to give precise information as to the loss in working up the reduced silver; 600 cells having been accidentally allowed to run 
down, the loss in extracting and fusing the silver was $1 \cdot 38$ per cent.

Chloride of silver is charged at three-quarters of the price of silver; and the allowance made by Messrs. Johnson and Matthey for returned silver is about 6 per cent. less than the price at which they sell it. The charge for fusing and casting the chloride is $\mathrm{I} d$. per rod. Hence it appears that though the prime outlay is considerable, the cost of renewal is small, and a battery of these elements represents a certain amount of capital which might be realised at any moment. The labour required for setting up this battery is comparatively very little, and, this done, the element, from the insolubility of one of its electrolytes, is capable of standing idle for any length of time without other detriment than increase of internal resistance; this increase, too, occurs but slowly, many months elapsing before it rises from, say, 5 to 20 or $30 \mathrm{ohms}$ per cell. Moreover, the element is notably clean and compact-a case I4I cms. high, $107 \mathrm{cms}$. wide, and $43 \mathrm{cms}$. deep, will hold 1,200 . The details carefully given by Messrs. De La Rue and Müller of their very great experience of this valuable cell will probably be hailed as a boon by the many who have occasion to make use of roltaic batteries.

The accompanying diagrams show some of the apparatus which were specially devised by the authors to meet the insulation requirements of the high electromotive force they employed.

For instance, the ordinary form of doublereversing-key could not be used with this great battery, in consequence of the formation of an arc when the key is raised with the object of breaking the circuit. Figs. 2 and 3 show the new form devised by the authors. $\mathrm{H}$ is the handle fixed to the ebonite axis, which has metallic collars A $Z$ at its extremities; these are connected to the springs $S S^{\prime}$ by wires inserted in the axis. The battery wires are led to $A$ and $z$. The standards $\mathrm{B}$ and $\mathrm{B}, \mathrm{B}^{\prime}$ and $\mathrm{B}^{\prime}$, are respectively connected by diagonal wires between the ebonite plates $\mathrm{E}$ and $\mathrm{E}^{\prime}$. Fig. 3 shows the open circuit position. In Fig. 2 the zinc pole is connected through $S$ to $B^{\prime}$ and the leading wire $\mathbf{N}^{\prime}$; the silver pole being similarly connected to $\mathrm{P}^{\prime}$. If now the handle $\mathrm{H}$ be thrown over to the right-hand side of the Fig. $2, Z$ will be connected to $B$ on the right side, thence through the diagonal wire to $B$ on the left side of the figure, and to $\mathrm{P}^{\prime}$, while $\mathrm{Ag}$ will be similarly connected to $\mathrm{N}^{\prime}$. In this key, on breaking contact, the arms S $\mathrm{S}^{\prime}$ can be removed from the standards $B B^{\prime}$ by a distance greater than that to which the arc can be drawn out.

Fig. 4 shows the micrometer discharger, by means of which the authors are able to measure the length of the spark to within $1000 \%$ of an inch. Its construction is sufficiently obvious; it need only be remarked that the nut fixed in the crosshead at the top of the frame through which the screw works is in metallic communication with the clamp c, and is divided horizontally into two parts, which are pressed asunder by three spiral springs in order to prevent shake or play of the micrometer screw.

For special experiments it was necessary to design and have constructed a commutator capable of reversing the current many times in a second; that shown in Fig. 5 represents the most convenient form; it is capable of reversing the current 352 times in a second when the handle is turned 240 times in a minute. It will be seen that each revolution of $A, B, C, D$ reverses twice. The figure is so distinct as scarcely to require any description; $B$ and $D$ are of one piece of metal, and also $A$ and $C$ of another, the spring. conductors making contact at $90^{\circ}$ distance from each other; each of the uprights supporting the axis of the revolving disc is in metallic connection with its respective insulated clamp. In the position shown in the figure the positive current passes from Agto the upright supporting the axis of the revolving disc, and through the right hand spring to the wire plate $\mathrm{A} g^{\prime}$; the negative current from $z$ to the upright on the other side of the revolving disc, only partly seen, thence through the upper spring to $Z^{\prime}$.
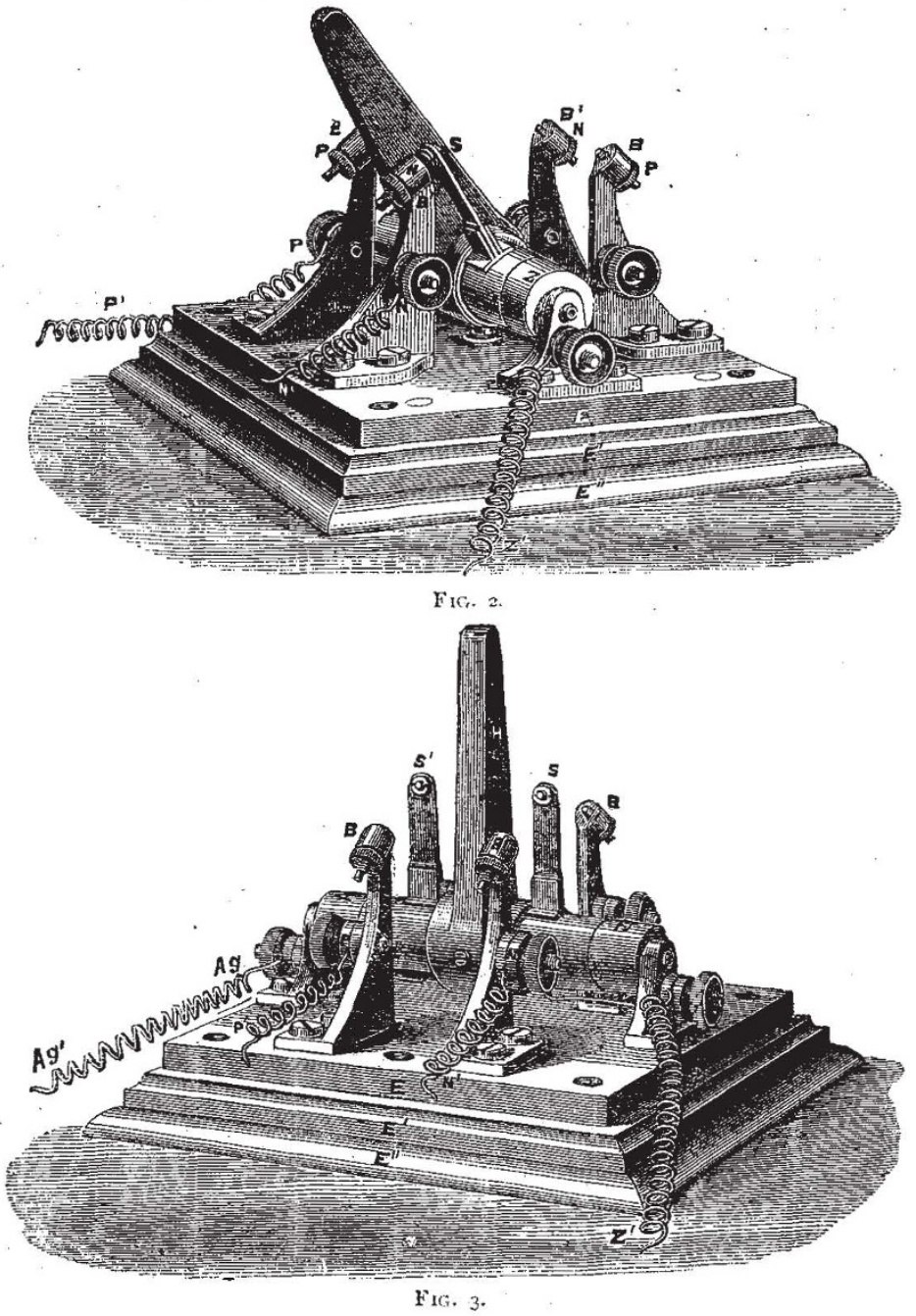

FIG3. 2 and 3.-Doub'e Reversing Key.

Besides this, the authors had a contact breaker very similar in appearance, and shown in situ in Fig. 7 on the top of the dwarf cabinet of battery No. I, containing I,080 powder-cells; this cabinet top is of ebonite, and forms their ordinary working bench. $\mathrm{M} \mathrm{M}^{\prime}$ represents a revolving mirror, which has a multiplying wheel, and in which the reflection of the discharge in a vacuum tube can be seen. In the circuit was a set of coil-resistances from I to I, 00,000 ohms, specially insulated, the wires running in grooves on insulating cylinders made of paraffined cardboard, in order that they may be kept at a distance; besides this set of resistances there were four 
tubes of liquid having a maximum resistance of about $2,4,6$, and 33 megohms respectively; all but one were furnished with adjustable wires by which their resistance could be diminished; two are charged with equal parts of water and glycerine, two with distilled water; each has a plug to throw the resistance out of circuit.

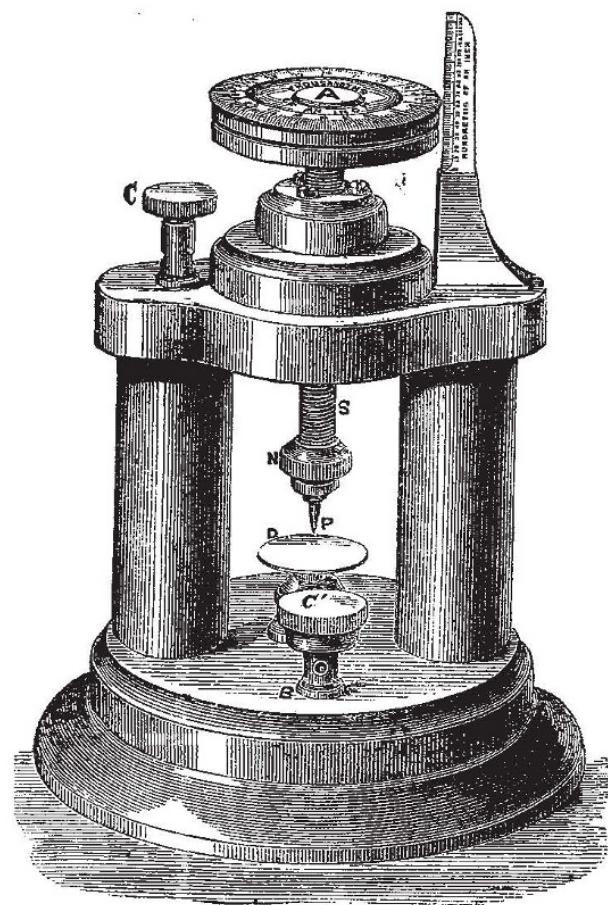

Fyc. 4.-H.crometer Discharger.

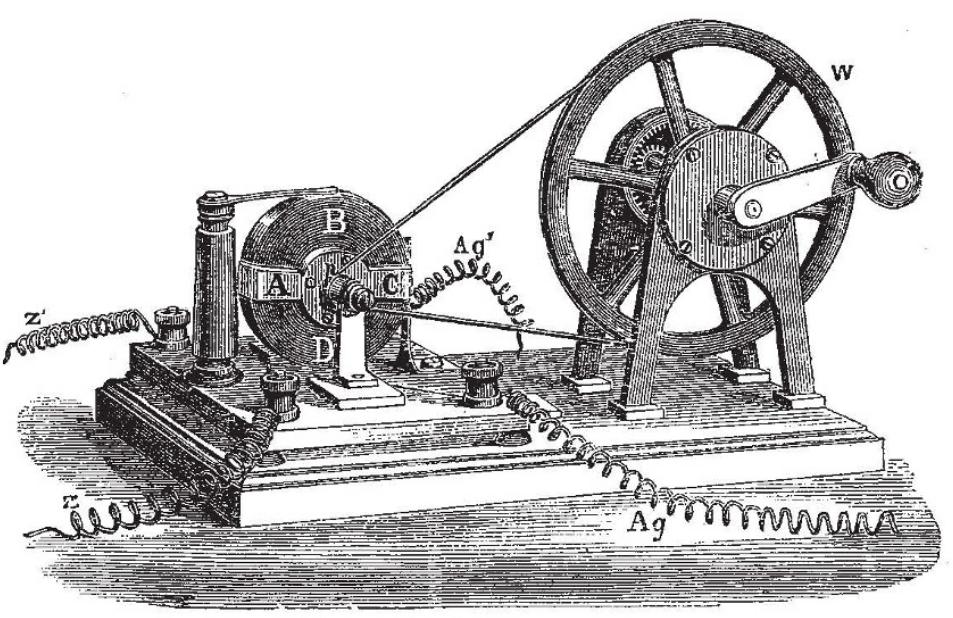

FIG. 5.-Rotating Commutator.

These resistances gradually diminish by the absorption of ammoniacal salts from the atmosphere, and this necessitates occasionally the entire renewal of the fluid.

As has been already stated, the paper deals principally with the discharge in gases at atmospheric pressure. Very elaborate series of measurements were made of the

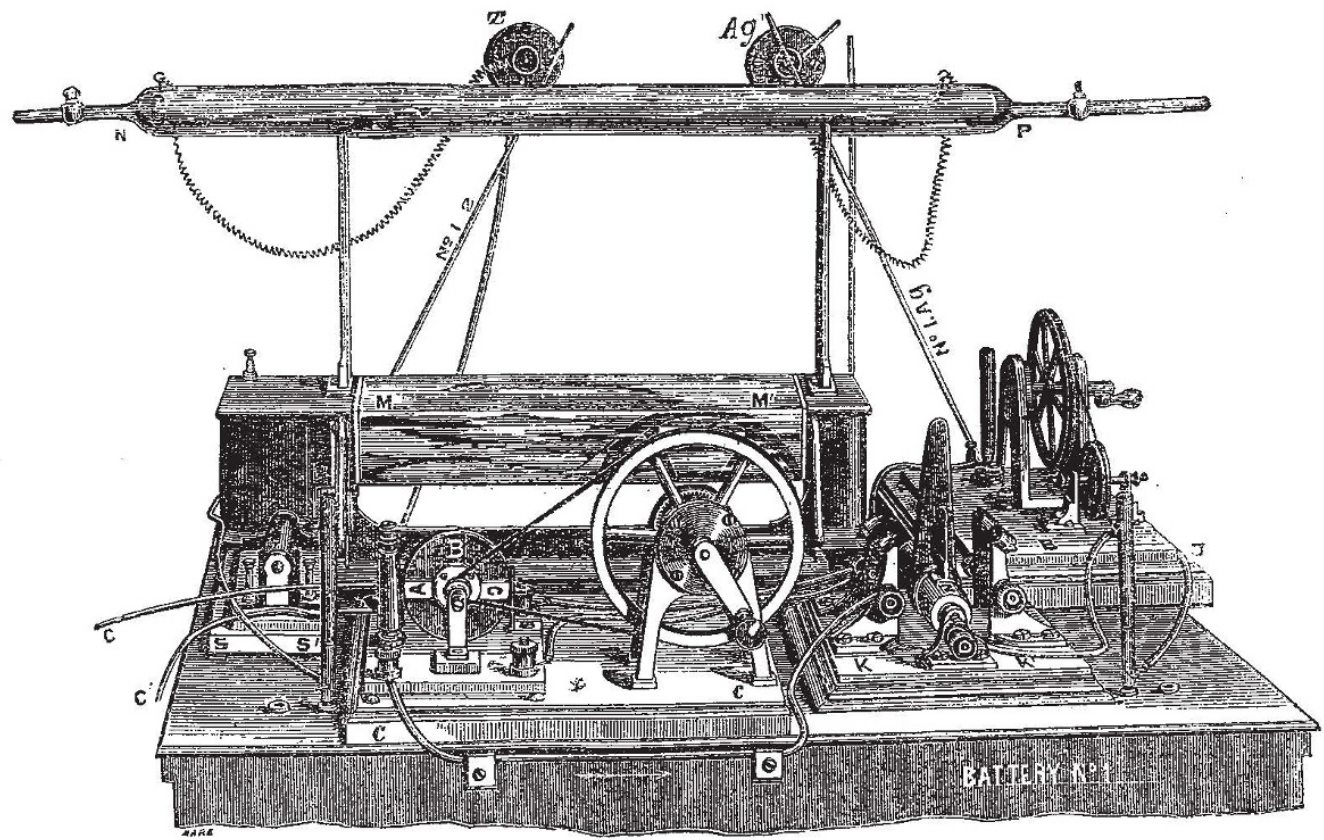

Fic. 6.-Table with Apparatus in situ.

potentials (i.e., differences of potential) requisite to produce / concentric cylinders, the diameter of the outer being con* discharge at various distances between (I) plane surfaces, stantly 0.4895 inch, that of the inner being varied from (2) spherical surfaces of 3 -inch radius of curvature, (3) $0^{\circ} 4733$ inch to $0^{\prime} 2865$ inch, (4) a paraboloidal point and a 
disc, (5) paraboloidal points. The results of each series a diagram (Fig. 7) giving a comparative view of the mean are clearly set forth in the tables and plates which accoin. pany the original memoir; here we have only space for

curves of all the measurements.

An inspection of the diagram will show that with plane

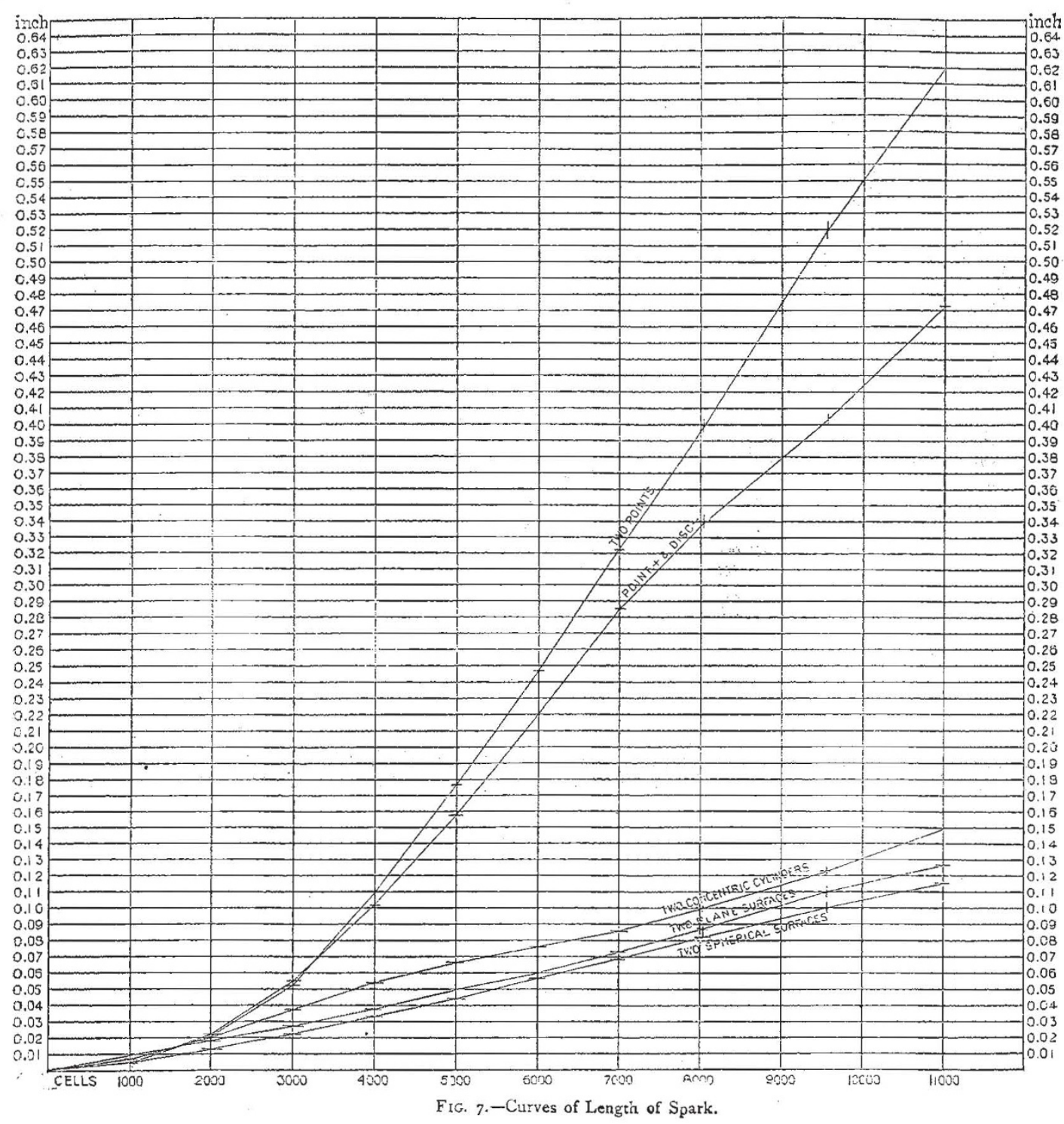

or slightly convex surfaces the potentials necessary to produce discharge at various distances are not proportional to the distances when these are small (less than $0.025 \mathrm{inch}$ ), but tend to become so as the distances are

\section{PHYSICS IN PHOTOGRAPHY}

II.

WE have hitherto treated the question of a sensitive compound from what may be called a chemist's point of view, but it has also its physical aspect, and to enable us to understand what has recently been done in photography this lat'er must be briefly touched upon. To commence with, we are met with a difficulty in nomenclature which ought not to exist. Unhappily chemists and physicists employ the term molecule in a different sense. The physicist's molecule, for instance, in one 1 Continued from p. $43 \mathrm{r}$. increased. These results confirm and extend those published by Sir W. Thomson.'

\section{(To be continued.)}

place is clefined ${ }^{2}$ as " a small mass of matter the parts of which do not part company during the excursions which it makes when the body to which it belongs is hot." To avoid misapprehension the expression molecular group will be used for the physicist's molecule for want of a better, the word particle being rather too indefinite, and being usually applied to a group of molecules of visible size, a state of aggregation which is by no means necessary. The question as to the possible variation of the number of molecules composing a molecular group has not been entered into, as it would be trenching on ground 